\title{
ENGLISH AS A MEDIUM OF INSTRUCTION IN SECONDARY SCHOOLS IN SRI LANKA: CHALLENGES
}

\author{
Ameesha Wijayatunga \\ School of Education, University of Leicester, $U K$
}

\begin{abstract}
Sri Lanka introduced English as a medium of instruction in Public Schools country-wide in 2001 as a means of preparing the younger generation to face "Globalization" effectively. Such opportunities, though existed even before, had been limited to a few urban elite schools. Fifteen years of implementation of this policy needed a critical analysis. This paper reports an investigation of the challenges in implementation and expansion of English medium classes in schools. The research is based on a survey carried out with a sample consisting of English medium teachers and students. The study found that those who teach in English medium in urban schools are enthusiastic but majority of teachers, are not proficient enough in the language to teach in English. Comfortable and attractive classroom with up to date supporting technologies, effective training of teachers, and support by management of the schools will lead to better results. The students in English medium also needs support in improving language skills. They have an edge over others when pursuing higher education which is mostly in English medium. The paper concludes that the policy has been successful so far but it requires more focused resources if it is to expand successfully country-wide and provides some recommendations for way forward.
\end{abstract}

Keywords: English, medium of instruction, Sri Lankan schools, Challenges

\section{Introduction}

Sri Lanka introduced English as a choice of medium of instruction in Public Schools country-wide in 2001 as a means of preparing the younger generation to face "Globalization" effectively. Such opportunities, though existed even before in the country, had been limited to a few urban elite schools.

After more than fifteen years of implementation of this new policy for the second time into the curricula many issues and complaints have been made. There are still a limited number of schools conducting classes in English medium. Even in those schools majority of students opt for taking classes in vernacular medium, depending on their mother tongue. Lack of qualified teachers and their proficiency in teaching in English restricts the expansion of student numbers and more schools implementing the policy.

English is not a popular medium of instruction in remote schools since parents have the fear that their children may not perform well in school due to their not being fluent in the language and possible communication gaps leading to difficulties in understanding the subject matter properly. Such parents have no other option but let the children study in their mother tongue. Furthermore, the communities in suburban and rural areas where economic hardship is prevalent are more focused on making sure their children do well in school and enter the university since that is the best way to climb the social ladder. However, the key courses at the bachelors' degree level such as medicine, engineering, law and management in the Sri Lanka Universities are conducted in English medium.

Even in urban schools only about $20 \%$ of the students choose English as the medium of instruction. At present Science, Mathematics, History, Health Science, Geography, Business Studies and Information and Communication Technology are taught in English medium in urban and few suburban schools from Grade 6-11 for students of General Certificate of Education (GCE) Ordinary Level. However, all the subjects in Biological Science, Physical Science and Commerce streams are taught in English at GCE Advanced Level in a very few selected urban schools. Majority of public schools still use vernacular languages. 
Coleman (2010:10 and 11) identified some of the roles that English has been playing in development context: increasing employability, facilitating international mobility (Migration, International mobility, higher education etc), unlocking development opportunities, accessing crucial information and acting as an impartial language in contexts where other available languages would be unacceptable. These four broad areas are very much applicable to Sri Lanka particularly as English is the only linking language for the different communities speaking either Sinhalese or Tamil language. Unfortunately, no matter how sound the objective of any reform effort is, the final outcome depends on the way it is implemented and how it is viewed and accepted by the society.

This qualitative type research is based on a survey done in three schools, one selected from each of the three main Educational districts of Sri Lanka. Two respondent groups were selected as the sample (RG1) among English medium teachers and (RG2) English medium students. The main purpose of study is to investigate the barriers to implementation and expansion of English medium classes in schools as perceived by the teachers and students. The overall research focused on four aspects (i) challenges teachers and students encounter when teaching/learning in English (ii)whether studying in English provides better opportunities to students in their future (iii)The reasons that makes students reluctant to study in English and(iv) suggestions to overcome the difficulties and make this policy successful

\section{Literature Review}

Globalization and the emerging of new technology have made the impact in such a way that many societies are affected on an unprecedented scale. "Because of the need to have a shared linguistic medium, English has assumed its place as the language of communication within the new linguistic global order"(Marsh,2006:29)

\section{Globalization and Medium of instruction in schools}

English as a "lingua franca" can be described as the contact language used between people who do not share the same native language or cultural background. Today, a wider range of people use English as an additional language. It is estimated that over $80 \%$ of interactions in English worldwide are between non- native speakers (Graddol, 2006). In future, it is expected in this interconnected and independent world, English will undoubtedly take the first position as a lingua franca for socio-economic development over the next fifty years.

English is viewed as an essential lever for success in the globalising economies, and thus carries the mantle of the 'language power' (Marsh,2006). English has taken its place as the medium of instruction in many countries even in those where there are rich cultures and languages spanning into thousands of years. The adoption of English may result in positive or negative educational outcomes. In some poorest countries in the world the use of foreign languages as medium of instruction has directly linked to educational exclusion and failure. In some countries, choosing English as the medium of instruction has led to high dropout rates. For example, school wastage in some countries in sub-Saharan Africa is huge (Marsh,2006:30). But in many other countries it has been introduced using appropriate educational principles, proper teacher training leading to successful and sustainable outcomes. Philippines, for example, has succeeded in teaching in English medium, hence produce English speaking workers in every field to the world. This has led the country to consider foreign remittance as its main source of income.

\section{English as a medium of instruction in developing countries}

English is used as a medium of instruction in many developing countries, especially in countries where the native population groups have different mother tongues. Usually the perception towards using English is very low among the common people. In Pakistan where the official languages are Urdu, English and Punjabi, many other local languages are used as the medium of instruction in rural schools, which has hindered such children to speak country's official languages, preventing them from qualifying for state employment. In multi-ethnic 
countries, for example Pakistan, using a link language such as English as the medium of instruction is quite critical. English is used as the medium of instruction only in urban cities in Pakistan, which has created social issues in the society. The elite sends their children to expensive private schools and speaks in English at home, where as;

"others learn English from their teachers in the low-fee schools who by no means really acquire proficiency in the English language. They are ghettoized in the job market and never reach the lucrative jobs" (Ahmed et al, $2013: 4$ )

In Africa, mostly the foreign languages are used as the medium of instruction from primary classes. This is mainly due to colonization.

"All former British Colonies have English, all former French colonies have French, former Portuguese colonies have Portuguese, only one Spanish Colony has Spanish, as language of instruction" (Obondo, 1997:26).

"In education systems of many African countries, the use of indigenous languages is limited to the first three-four grades of schooling. In later years they learn their first language only as a subject. It is not possible for a man to walk with legs of others, see with the eyes of others, it is equally or perhaps more impossible for him to think in a language of others" (Ahmed et al, 2013:3, quoted in Rehman,1997).

Therefore, mastering ones' own language is critical.

\section{English as a medium of Instruction in Sri Lanka}

As for the Sri Lanka's context, English was the medium of instruction in many schools in Sri Lanka during British Colonial period. Later in 1940s, after considering the issues such as language barriers and the rise of nationalism, the government gradually changed the medium of instruction in to vernacular languages.

With the introduction of free education in the country in 1945, by Educational Reforms in 1942, even the poorest of the poor got an opportunity to have the basic school education. Due to the fact that having English as a medium of instruction had created a class disparity among urban and rural people and those who study in English medium were only qualified for the "white collar jobs", Sinhala or Tamil was introduced to all schools as "the" medium of instruction. The two main suggestions made by the 1942 reforms committee were: (i)make a good education available to all children free of charge, so that education ceases to be a commodity purchasable only by the urban affluent, and (ii)make national languages the media of instruction in place of English so that opportunities for higher education, lucrative employment open only to small number of the urban affluent, would become available to others as well. After 60 years, Sri Lanka realized that there are more advantages in introducing English as a medium of instruction than the disadvantages it experienced in the colonial era. However, in the present context English is used as a medium of instruction in selected urban and suburban schools. In such schools too, majority study in vernacular language. Unless English medium is used island-wide and made compulsory in some subjects, there is a high probability that Sri Lanka would create the same situation as in present Pakistan and old Ceylon.

Christ (1997) underscores the importance of language in the education system. According to him the nature and quality of educational institutions is determined by language of instruction and attitudes towards the language. Positive attitudes towards language and medium of instruction are likely to steer learning beyond the classroom situation through the interaction between learners and between learners and materials. On the other hand negative attitudes will affect the learners' attainment of skills and knowledge. Therefore, creating the positive attitude in students is very important. 
It is true that there are challenges in implementation and development of such a policy. But there are ways and means that will make them successful and popular. Efficiency in teachers, enthusiasm in students as well as support from parents and management are mandatory. Efficiency and competency in teachers can only beimproved through proper teacher training that would emphasize both the training in teaching the subject in English and handling the language.

The issues in a class room learning environment can also be minimized by using;

"a comfortable and attractive classroom in an environment which will be able to stimulate learning, by selecting the right methodology and teaching style and by using Information Communication Technology to apply new technique in teaching and learning"(Mansor,et al 2011:130).

Thus, teacher training is quite important not only for teachers of a foreign medium of instruction, but all other teachers as well. A well-planned teacher training course, which includes methodology of teaching, class room management and subjects like Education Technology which helps student teachers to learn how the lessons can be planned with teaching aids and Information technology, is very important.

Competent teachers are those who know their subject, are willing to answer students' questions, are approachable, and also have a sense of humour. To perform the role of a competent teacher of English medium, they should definitely be competent in the language. Competent teachers are able to provide assistance to learners, explain concepts better than a teacher who would try to come down to the level of students and use wrong language to explain lessons. Regular language improvement programmes plays a vital role in increasing and bringing up competency in teachers.

In summary, there are challenges and issues in non-English countries when English is used as a medium of instruction. Lack of resources, lack of competent teachers, competency level of students, and perception of the people in the country may decide the implementation and growth of such a policy. There have been recorded successes as well as failures in using a foreign language as a medium of instruction. Positive attitude towards the language, proper teacher training, using of technology and by providing additional language support will minimize the challenges faced by both teachers and students. It is believed that those who study in English medium get better opportunities in their career as well as in life, even though many parents in rural and sub urban areas would prefer their children to study in vernacular language.

No research has been carried out in secondary schools in Sri Lanka to ascertain the impact of using English as a medium of instruction in relation to the issues discussed above. This study therefore aims to investigate the challenges students and teachers face in this context.

\section{Investigation}

\section{Population}

This case study was carried out based on a survey in three public schools in the popular Education districts in Sri Lanka namely, Colombo, Kandy and Galle. The survey included the responses from a sample of teachers and students from each school. The schools were selected from the few schools which conduct classes in English medium. Purposive sampling technique and convenience sampling were used, since there were not many schools conducting English medium classes and considering the ease of access respectively.

Teachers group (Respondent Group1, RG1) was selected from all the teachers who teach in English medium classes. They were expected to have a good knowledge of the difficulties and challenges in teaching in English 
medium. A selected sample of students from Grade 11 English medium classes (Respondents Group 2, RG2) were also chosen to investigate the difficulties face by the learners when studying in English medium.

\section{Sampling}

Three main education districts in Sri Lanka, namely Colombo, Kandy, Galle were selected for the study. One school was selected from each district. Considering that the total number of English medium teachers in three schools was 61, all teachers from each school were invited to take part in the survey. Furthermore, since there was a total 156 students in Grade 11 English medium classes in all three schools, 80 students were selected randomly to get a sample of $>50 \%$. Grade 11 was selected purposefully since they were regarded as mature enough to participate in a survey.

The study adopted convenience and purposive sampling methods for selection of schools and Grade of the students. The reason for this form of sampling was because the researcher has her personal contacts with the management of the school and its staff. Therefore, the respondents were comfortable in expressing their opinion.

In two schools, there was only one class of English medium for each grade, where less than 42 students were studying. Twenty students studying in Grade 11 were selected from those two schools randomly for the study to represent $50 \%$ of the total population. The third school had two classes for each Grade with 78 students in Grade 11, therefore 20 students were selected from each Grade 11 class randomly, using the register of daily attendance. The register of daily attendance was used as the criteria to select students (every even number was chosen), but if the relevant student was absent, the next number was selected.

\section{Data collection methods and instruments}

Since both factual information and attitudinal information were needed from teachers as well as learners, two questionnaires were used, one for each group. Based on the assumption that the researcher's association with the teaching staff would make teachers more comfortable and reliable in expressing qualitative responses to the questions (Eg. Agree,Disagree) than responding on a quantitative scale, a four point Likert scale, was used with teachers. Same technique was used with students since it was considered to be less time consuming too. The questionnaires sought to establish the perception of teachers and students on English medium education and how it can be made popular among schools.

The questionnaire for teachers was constructed strategically to capture all factors that are likely to prevent successful implementation and expansion of English medium Education in Sri Lanka. It was designed with simple questions which could be easily answered without any ambiguity. English was used since both the groups are teaching or learning in English.

The background teacher information such as age, educational qualifications and professional qualifications was sought to establish quality of the responses. The students were selected from Grade 11 classes, since they are matured enough to participate for such survey. Gender was used as the background information, even though it was not useful since two of the schools were girls' schools.

The questions in both questionnaires were framed to cover the research questions and to capture the main issues identified in the literature such as (i) Are the issues in other developing countries when implementing English as a medium of Instruction in schools common to Sri Lankan context (ii)Do the teachers get enough support(ii) Doparents' attitudes affect the students when selecting a medium of instruction in school (iv) what steps needed to be taken to make teachers and learners to be more enthusiastic towards such a policy. 
The RG 1 was informed in advance about the research by the Principals of the particular school and RG 2 was informed through the teachers. Therefore, they were knowledgeable about the study. In addition, parents of the student population were also informed in advance with a letter of permission, prior to the date of conduct.

The researcher administered completing the questionnaire with the help of Management and teaching staff. This process coupled with the information provided to the respondents in advance about the survey, ensured the reliability and consistency of the responses.

\section{Limitations}

The survey sample size had to be limited to three schools, Further, the study does not cover the suburban and rural areas, since English medium is not popular in such areas as yet.

Literature on use of English as a medium of instruction in Sri Lanka is very limited. However, the researcher has utilized limited work found in the literature and adopted the available work to address the issues relating to Sri Lanka to minimize the own biases towards the subject addressed. In the absence of the such literature and similar past research in the context of Sri Lanka, the validity of the responses was cross checked and confirmed with the researcher's own experience and the general perception among the public (expressed in the radio and television programs and in newspaper reports) on the use of English as a medium of instruction.

\section{Analysis and Presentation}

\section{Background information}

In Sri Lanka about $70 \%$ of teachers are female. But the composition of teachers participated in the research demonstrated that the proportion of male teachers ( $40 \%$ of the sample) teaching in English medium seems to be higher than the national average. Further, $87 \%$ of the teachers in the sample are over 30 years. Over two thirds of the sample have qualifications equal to or more than a bachelor's degree. As for the period of service $87 \%$ of them have more than 5 years of service experience in teaching. Both these groups form a large majority of the respondents (53.3\%) who indicated that they highly enjoy teaching in English medium. These statistics can lead to two observations. Large majority of those who teach in English tend to have qualifications beyond the secondary school level and they have obtained those qualifications in English medium (About $87 \%$ of the teachers in the sample have studied in English medium after high school certificate while the others had their entire education in their mother tongue). Also, the mature teachers with longer years of experience seem to be more interested, comfortable or chosen to teach in English medium. Also they have more time for preparation for classes as majority of those younger teachers (below 30 years) indicated that they find very little time for preparation (27\% of the total). Mature teachers may have a higher demand too, to conduct classes in English.

Examining professional qualifications, it is found that $80 \%$ of the teachers have either Postgraduate Diploma in Education or a special training to teach the respective subjects in English. It is also observed that two thirds of the sample is involved in teaching technical subjects such as Science, Math and Information and Communication Technology (ICT). There are several reasons for this. One may be that the demand for these subjects to be taught in English is higher compared to other subjects. Another reason may be that a majority of teachers who have studied in English have technical background since higher education in these areas is in English medium and therefore the availability of English medium teachers for technical subject is higher compared to other subjects. These reasons further confirm that reliability and the validity of information provided in the responses (or the quality of the responses). 
Table 1: Summary of the background information of the survey group 1

\begin{tabular}{|c|c|}
\hline & Percentage \\
\hline \multicolumn{2}{|l|}{ Gender } \\
\hline *Male & $40.00 \%$ \\
\hline *Female & $60.00 \%$ \\
\hline \multicolumn{2}{|l|}{ Age } \\
\hline$* 25-30$ & $13.33 \%$ \\
\hline *31-35 & $33.33 \%$ \\
\hline *36-45 & $46.67 \%$ \\
\hline$*>45$ & $6.67 \%$ \\
\hline \multicolumn{2}{|l|}{ Education } \\
\hline *Secondary Level & $13.33 \%$ \\
\hline$*$ Diploma & $20.00 \%$ \\
\hline *Bachelors & $13.33 \%$ \\
\hline *Postgraduate Diploma & $40.00 \%$ \\
\hline *Masters & $13.33 \%$ \\
\hline \multicolumn{2}{|l|}{ Medium of Instruction } \\
\hline *English & $86.67 \%$ \\
\hline *Sinhala/Tamil & $13.33 \%$ \\
\hline \multicolumn{2}{|l|}{ Period of service } \\
\hline$*<5$ years & $13.33 \%$ \\
\hline *5-10 years & $53.33 \%$ \\
\hline *10-15 years & $26.67 \%$ \\
\hline *15-20 years & $6.67 \%$ \\
\hline \multicolumn{2}{|l|}{ Professional Qualifications } \\
\hline$* \mathrm{PgD}$ in Education & $46.67 \%$ \\
\hline *Trained in English medium to teach relevant subject & $33.33 \%$ \\
\hline
\end{tabular}

\section{Challenges in teaching and learning in English}

This section addresses the challenges teachers/students encounter when teaching/learning in English.

All the teachers interviewed seem to enjoy teaching in English medium classes. However, $80 \%$ of the teachers feel that the lack of teaching material in English in comparison to those in mother tongues (Sinhala and Tamil) is a challenge they face. Only $20 \%$ of them thought it is not an issue. Similarly, $80 \%$ of the teachers feel that they are more effective teaching the respective subjects in mother tongue. Of them, about $13 \%$ had this feeling strongly. Also, about $87 \%$ of the teachers thought the students would have been more responsive if they are taught in their mother tongue. This observation can be related to the analysis of Marsh (2006) in Africa that choosing English medium has led to higher drop-out rates. Also, Ahmed et al (2013) stated that it is equally or more impossible for one to think in a language of others.

This is particularly apparent since more than $90 \%$ of the teachers felt that the students' fluency in English is average at the time of opting to follow classes in English medium. Even in that case more than $70 \%$ of the teachers thought the use of the mother tongue in English medium classes when necessary is not the best way to 
come out of this situation. Interestingly, $68 \%$ of those students in English medium classes thought that language is not an issue.

These challenges can be overcome by adjusting the language to suit level of the students. However only $40 \%$ of the teachers thought that would help. All the teachers indicated that taking examples to explain the concepts would be a good approach to deliver subject matter to these classes where the language skills of the students are weak. Also encouraging students to read further will also help to improve this situation. Even though $80 \%$ the teachers thought that subject material in mother tongue is readily available compared that in English medium more than $95 \%$ of the students disagreed. This may be because $80 \%$ of the teachers themselves indicated that they can find additional material in the school library and in the internet which they have access to. At the same time $58 \%$ of the students thought that they need additional tutoring because they study in English medium classes. This may be because, while the teachers think that availability of reading material is more important, the students are more inclined to be tutored rather than trying to cover any gaps through additional reading.

The other critical issue is the training opportunities available for capacity building in teaching in English medium. All the teachers felt that there were no regular training opportunities to update their subject knowledge and to improve language skills in English so that they can teach effectively. In the opinion of $60 \%$ of the teachers, school managements are reluctant to allow teachers to go through training programs and hence this issue becomes even more serious. Of the sample, $73 \%$ felt that the regular teacher training programs they had gone through did not provide adequate support for effective delivery of classes in English medium. However, $80 \%$ of the teachers indicated that they prepare adequate support material in advance to help the students. About 27\% thought that the time available for preparation is limited. It is indicated by Mansor,et al (2011) that some of these issues can also be minimized by using by selecting the right methodology and teaching style and by using Information Communication Technology.

\section{Studying in English and opportunities for progress}

Does studying in English provide better opportunities to students in their future? All the teachers are aware of many advantages to students in learning in English as against following classes in mother tongue. Particularly, all the students in the English medium classes feel that their prospects for higher education and career after secondary school are far greater when studies are undertaken in English as against studying in their mother tongue. Only $10 \%$ of the students felt that their decision was based on parents' pressure. The literature (Graddol, 2006 and Marsh 2006) confirms that English being a widely used medium among different communities opens up many opportunities. The experience in Sri Lanka higher education sector also shows that many of the highly sought after courses such as medicine, engineering, science, law, management and economics available in the universities are conducted in English medium. Naturally those who studied in English have an edge over others when understanding subject matter during early years in the university. However, this may not be the case in the later years since others also have a chance to catch up with the language.

In the case of career opportunities, those who study in English likely to perform better in interviews mostly conducted in English. This is particularly the case in the private sector institutions most of which use English as the medium of instruction and hence emphasizes on English language skills. Therefore, those who study in English tend to have an edge over others in the private sector job market.

\section{Students reluctance to study in English}

It would be important to examine the reasons that makes students reluctant to study in English.

Based on the survey, there are several reasons for reluctance of the students to study in English. About $33 \%$ of the students in the English medium classes thought that they would have learnt more of the subject if it were 
conducted in the mother tongue. This means, it is highly likely that their colleagues in the classes conducted in the mother tongue (survey could not include these due to time and resource constraints) would have been much more convinced that English medium would have led to lesser understanding of the subject matter for them. About $58 \%$ of the students in the sample expressed parents' feeling that their children would far better if they studied in mother tongue.

A majority of the students in the English medium classes (58\%) expressed that they need additional tutoring due to the selection of English medium which means economic factors also come in to the equation. This means probably the students in these classes tend to be from the economically better off families who can afford such additional expenditure. Therefore, it can be argued that those students who cannot afford such expenses are reluctant to study in English.

The other aspect is the parents help at home extended to their children to comprehend subject matter taught in the classes, particularly at lower secondary school level. This is a very common phenomenon in the middleclass households in Sri Lanka. This means the ability of the parents to understand subject matter in the medium their children are taught plays a critical role. About $40 \%$ of the students in the English medium classes thought this is a reason for parents not to opt for English medium for their children. The large majority of the parents of these students in their generation went through education only in the mother tongue due to restrictions in studying in English.

Also, the parents not being aware of the benefits of learning in English and the feeling that they lose control of the children (due to perceived superiority complex of the students in these classes) may be some barriers for the students to take up studies in English medium, though only about 35\% students felt that way. About $63 \%$ of the English medium students felt that they have better standing among peers because of the medium they study and 53\% thought there is gap between them and others and hardly make friends in the other group. This clearly agrees with the analysis of Ahmed, Zaif and Tehseen (2013) in Pakistan how English as medium of instruction creates a class difference.

\section{Conclusions and Recommendations}

Teaching in English medium in non-English speaking country can always be challenging. This study has taken into consideration the challenges faced by both teachers and students in the classroom as well as the attitudes of parents towards sending their children to study in English medium.

Those who teach in English medium in urban schools are much enthusiastic in their work. But in Sri Lanka majority of teachers, except some of those who had been living in the main cities, are not proficient in English language. At present opportunities for teachers to improve their language are low. Even majority of the English medium teachers do not have opportunity to attend regular training/Seminars. At times, management may refuse to send the staff for seminars since they are held during school hours. Teaching material in English in comparison to the first language is less. Therefore, teachers find it difficult to prepare lessons.

The competency level of the students at the time of starting to learn in English medium is also average. Therefore, attention should be made to improve their language as well. Using of mother tongue when and where necessary is not the right way to make students understand the subject matter. Teachers should encourage using additional reading materials.

Parents believe that their children would perform better in their mother tongue. They sometimes are worried since they cannot help the children in their studies due to language barriers. 
A comfortable and attractive classroom, using of technology in the classroom, selecting the right methodology, effective training of teachers, and support by the Management of the school will give better results for the schools which have already implemented English medium instruction.

It is a wise decision to have English as a medium of instruction in Sri Lanka. It has been successful in the schools where it is implemented at present. But if this policy to grow, it requires more resources. There is no doubt that Successful learning of English as a second language at the primary level decides whether a student has an adequate level of competency in learning in English. Therefore, appointing competent and good ESL teachers to all schools in the country is necessary.

Mass media can be used effectively in teaching the language as well as providing additional subject knowledge by telecasting more Educational programs.

Encouraging students to read extra reading materials, use web to find out articles relating to the lesson, provide them opportunities to see documentaries, giving many examples when explaining a lesson will be the steps that can be taken by the teachers in order to help the students who are average in the language.

It is important to provide regular training and seminars for the teachers of English medium. More teachers to teach in English medium should be recruited and appointed in suburban areas.

Regular teacher training should be conducted with the help of Regional English Support Centres (RESC),Zonal Education Offices during the week end and attending to those workshops or seminars should be made compulsory.

Parents of the secondary students should be made aware of the benefits of learning in a global language and the opportunities their children would be getting in future.

Sinhala/Tamil language, Sinhala/Tamil Literature, Religion can be taught in vernacular languages to improve the first language skills, but all technical and Sciences can be taught in English.

Project method, discussion method should be encouraged among teachers when teaching in classrooms to improve student participation.

Training in ICT should also be considered in order to facilitate teaching and learning process.

\section{Acknowledgement}

The author would like to acknowledge the guidance given by her supervisor Mr. Martin Brewis, School of Education, at the University of Leicester, UK and her spouse Dr. Priyantha D C Wijayatunga of Asian Development Bank Head office, Philippines.

\section{References}

Ahmed,A., Zarif,T. and Tehseen.(2013)The role of medium of instruction used in Pakistani classrooms, Interdisciplinary Journal of Contemporary Research in Business, Vol 4,No12

Coleman,H.(2010)Developing Countries and the English Language:Rhetoric,risks,roles and recommendations, London:The British Council

Creswell,J.(2003)Research Design:Qualitative, Quantitative and mixed Methods Approaches 2nd Edition, London:Sage

De Silva, W.(2001) The Concept of a National System of Education, Reforming Education :Unfinished Task ,Colombo :National Institute of Education 
Foong,C.K.(2010) English for the teaching of Mathematics and Science(EteMS):From Concept to Implementation.

Graddol, D.(1997)The Future of English. London: The British Council

Lewin, K.(1993)Education and Development, Education for all, Policy and Planning, Lessons from Sri Lanka, DFID Educational papers No 6

Mansor,N.Badarudin,M. and Mat,A.(2011) Teachers Perspective of using English as a medium of instruction in Mathematics and Science subjects, International Journal of Instruction, Vol4,No2 http://files.eric.ed.gov/fulltext/ED522687.pdf online accessed August 6,2013

Marsh,D.(2006) English as medium of instruction in the new global linguistic order:GlobalCharacteristics,local consequences,(Pgs 29-31) available at

http://citeseerx.ist.psu.edu/viewdoc/download?doi=10.1.1.125.2388\&rep=rep1\&type=pdf online accessed on August 10,2013

Obondo,M.A.(1997).Bilingual Education in Africa:AnOverview.In In Cummins,J. and Corson, D.(Eds.).Encyclopedia of Language and Education:Bilingual Education,5.Dordrecht:Kluwer 